\title{
The prevalence of glaucoma in Bangladesh: a population based survey in Dhaka division
}

\author{
M M Rahman, N Rahman, P J Foster, Z Haque, A U Zaman, B Dineen, G J Johnson
}

Series editors: W V Good and S Ruit

Br J Ophthalmol 2004;88:1493-1497. doi: 10.1136/bjo.2004.043612

See end of article for authors' affiliations ....................

Correspondence to: Paul J Foster, Department of Epidemiology, Institute of Ophthalmology, Bath Street, London ECIV 9EL, UK; p.foster@ucl.ac.uk

Accepted for publication 14 June 2004
Background/aim: Few studies have reported on the epidemiology and clinical characteristics of glaucoma in south Asia. This project aimed to determine the prevalence of glaucoma of Dhaka, Bangladesh.

Method: A multistage, stratified, clustered sample was drawn from Dhaka Division, Bangladesh, using systematic sampling to identify individual subjects aged 35 years and older. Examination of all subjects included Snellen visual acuity, slit lamp examination (including gonioscopy and applanation tonometry) and a stereoscopic assessment of the vertical cup:disc ratio (CDR). In selected subjects, a threshold visual field examination was performed. Glaucoma was diagnosed on the basis of statistical abnormality of the vertical CDR combined with an abnormal visual field test, or in subjects with advanced glaucoma who could not complete field testing, a grossly abnormal CDR. If it was not possible to examine the optic discs and the subject was blind, glaucoma was diagnosed on the basis of a raised intraocular pressure.

Results: Of 3562 eligible subjects, 2347 were examined (66\%). Among people aged 40 years and older, the prevalence of definite glaucoma was $2.1 \%$ (95\% confidence interval: 1.5 to $2.9 ; 39$ people). The prevalence of definite and probable glaucoma was $3.1 \%$ (95\% Cl: 2.4 to $4.0 ; 58$ people) in subjects of the same age. Primary open angle glaucoma was the most common form of glaucoma, accounting for $75 \%$ of the total. Among cases of blindness not attributable to refractive error, $5 \%$ were caused by glaucoma. Glaucoma prevalence was higher in men than women, but did not show the typical increase with age. Conclusion: Glaucoma prevalence is relatively high in Bangladesh, although it accounts for only a small proportion of blindness in the community. It is estimated that there are approximately 586000 people 40 years and older with definite or probable glaucoma in Bangladesh.
G laucoma blindness affects over 6.7 million people, ranking only second to cataract (19.3 million) as a cause of blindness worldwide. ${ }^{1}$ Being medically and surgically irremediable, visual impairment from glaucoma presents a significant challenge to those concerned with prevention of blindness, both on an international and local scale. Unless detected at an early stage the prognosis for sight will be poor. ${ }^{2}$ Once detected, effective delivery of care still presents dilemmas that are specific to the individuals and their social environment.

The Indian subcontinent, including India, Pakistan, and Bangladesh, has a population of over 1.3 billion people. ${ }^{3}$ The World Health Organization estimates that the region is home to $23.5 \%$ of all blind people, around 10.5 million people. ${ }^{4} \mathrm{~A}$ population based study in urban Hyderabad found 30\% of adult blindness was attributable to cataract, while glaucoma accounted for $12 \%{ }^{5}$ A similar study in Nepal suggested that only $1.7 \%$ of blindness was attributable to glaucoma. ${ }^{6}$ The national blindness prevalence survey in Bangladesh found the overwhelming majority of cases were blind from cataract $(80 \%)$, while glaucoma was responsible for $1.2 \%$ of the total. ${ }^{7}$

Prevalence data for glaucoma in the Indian subcontinent are relatively scarce. The Hyderabad study found a prevalence of primary open angle glaucoma (POAG) and primary angle closure glaucoma (PACG) of $1.6 \%$ and $0.7 \%$, respectively ${ }^{8}{ }^{9}$ In neighbouring Vellore, Tamil Nadu, the rates were $0.4 \%$ and $4.3 \% .{ }^{10}$ Both these studies recruited people aged 30 years and older, although the Vellore study only recruited subjects aged up to 60 years. A recent report from Maduri, also in Tamil Nadu, found a prevalence of POAG and PACG of $1.7 \%$ and $0.5 \%$ respectively in people aged 40 years and older ${ }^{11}$ (the corresponding figures from Hyderabad were $2.6 \%$ and $1.1 \%$ ). With a population of 138 million, Bangladesh is home to a significant fraction of the total population of south Asia. This study sought to determine the prevalence of glaucoma and suspect glaucoma in the population of Dhaka Division, Bangladesh, aged 35 years and older.

\section{METHODS}

This project was given ethical approval by the Bangladesh Medical Research Council. Data collection began on 1 May 1997 and was completed 10 March 1998.

\section{Subjects and recruitment}

This study was carried out in Dhaka Division, in the central riverine area of Bangladesh. In 1994 the division had a population of 32667000 (30.7\% of the total of Bangladesh). Using data from work previously carried out in Bangladesh, ${ }^{12}$ a sample size of 2400 was calculated assuming glaucoma prevalence in the population aged 35 and older to be 3\%, with a standard error of the estimate of 0.01 and a design effect of 2 .

Within Dhaka Division in 1997, there were 130 thana (municipal areas). Of these, 105 thana were accessible by wheeled vehicle. The 25 inaccessible thana were excluded from the study. Each thana has 7-10 smaller administrative units known as unions. These, in turn, contain 10-15 villages with fixed, documented geographical boundaries. Villages are collections of permanent buildings (houses, school, mosque) and have a non-nomadic population. From the 105 accessible thana, 16 were randomly selected by the Statistical Bureau of the Government of Bangladesh. A list of accessible villages in each union in the respective thana was drawn up. Using random number tables a list of unions was randomly selected within the 16 thana, followed by a random selection of

Abbreviations: CDR, cup:disc ratio; IOP, intraocular pressure; PACG, primary angle closure glaucoma; POAG, primary open angle glaucoma 
Table 1 ISGEO scheme for definition and classification of glaucomatous optic neuropathy ${ }^{13}$

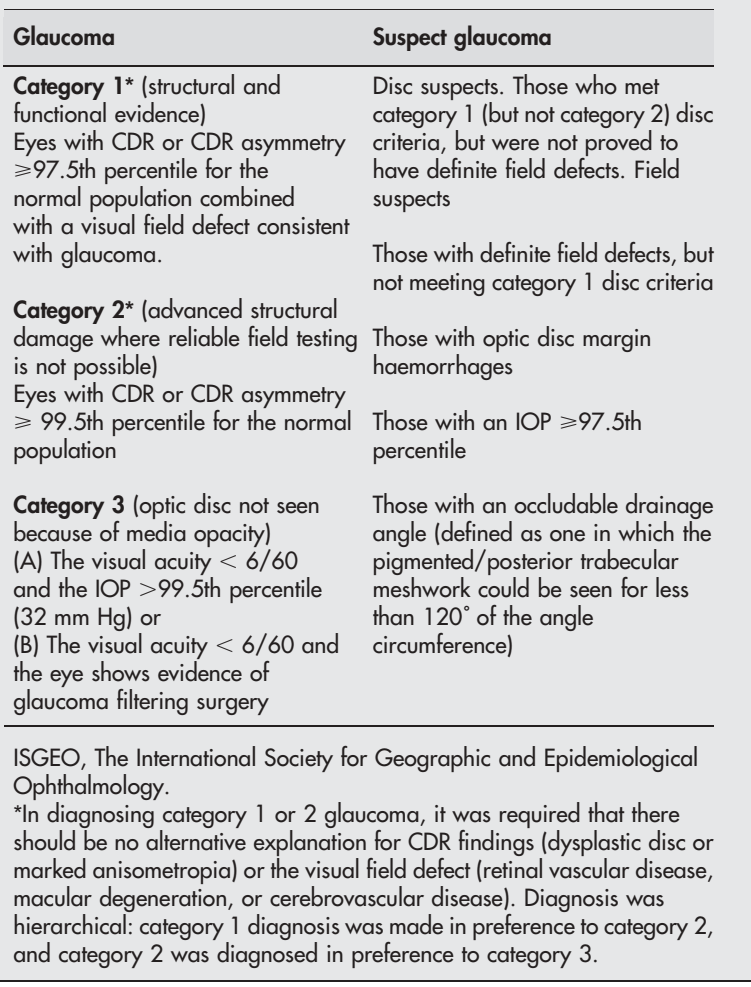

specific villages corresponding to the randomly selected unions.

A building was chosen as the study data collection site for each area. The project manager made a map of the area, and a census of the surrounding population was carried out to identify potential subjects aged 35 years or older. In all, 150 subjects were selected using a systematic strategy based on geographical proximity. If subjects had failed to attend l week after two invitations, the field motivator used the same strategy to select replacement subjects. This process was continued until 150 subjects had been examined. If the selected village contained less than 150 people aged 35 years and older, recruitment was continued in the next village lying immediately to the east.

\section{Ophthalmic examination}

A period of staff training was carried out at Islamia Eye Hospital, Dhaka. The technicians and field recruiter were briefed in questionnaire objectives and underwent instruction in data collection methods. Mock questionnaires were administered as part of the training. Verbal informed consent was given by all subjects who participated in the examination and questionnaire process. Visual acuity was measured at 6 metres using either a standard Snellen chart, an illiterate E chart, or a chart of Bangla letters designed to resemble a Snellen type chart. Acuity was measured with spectacle correction, or if no spectacles were worn and the visual acuity was $\leqslant 6 / 18$, a pinhole was used.

All slit lamp examinations were performed by the same ophthalmologist, who received a refresher course in assessment of glaucoma, and took part in glaucoma clinics at Islamia Eye Hospital for 1 month. The anterior segment of the eye was examined using a slit lamp (Model SL-3C, Topcon, Tokyo, Japan), to detect evidence of secondary glaucoma and previous ocular surgery. The cornea was anaesthetised using oxybuprocaine hydrochloride (Reman Drug Laborotaries Ltd, Dhaka, Bangladesh). Gonioscopy was carried out on all subjects, using a two mirror gonioscope (Model 905, Haag-Streit, Bern, Switzerland). Drainage angles were graded according to a modified Scheie's classification scheme (see diagnostic definitions). The tear film was stained with sodium fluorescein 2\% (Reman Drug Laborotaries Ltd, Dhaka, Bangladesh) and intraocular pressure (IOP) was then measured using an applanation tonometer ("Goldmann" model, Haag-Streit, Bern, Switzerland). The IOP was measured three times in each eye, and the pressure in the eye was taken as the median of the three readings.

The pupils of subjects with drainage angles graded as "open" were dilated with tropicamide 1\% (Opso Saline Ltd, Barisal, Bangladesh). The optic disc was then examined using $\mathrm{a}+90$ dioptre lens ("Volk", Mentor, OH, USA). Initially, the vertical cup:disc ratio ( $\mathrm{VCDR}$ ) was assessed without standard photographs or measurement graticule. Following a review of study procedure by a member of the advisory committee, standard disc photographs were employed in examination of the last 2000 subjects. The vCDR was recorded in units of 0.05. Disc margin haemorrhages were noted if present. The disc was examined through an undilated pupil if angles were judged narrow or closed. Threshold visual field testing was carried with a Henson CFA 3200 (Tinsley Medical Instruments, Newbury, UK), using a near refractive correction if $\mathrm{CDR} \geqslant 0.35$ or $\mathrm{IOP} \geqslant 18 \mathrm{~mm} \mathrm{Hg}$.

\section{Diagnostic definitions}

Gonioscopic examination was used to classify drainage angles as either open or narrow, if the posterior (usually pigmented) trabecular meshwork was seen for less than one third of the circumference of the drainage angle.

Visual field tests were judged to be reliable if fixation losses $\leqslant 33 \%$, false positives $\leqslant 40 \%$, and false negatives $\leqslant 33 \%$. Reliable tests showing defects $\geqslant 5 \mathrm{~dB}$ in depth in an area $12^{\circ} \times 12^{\circ}$ were considered probably glaucomatous, while those consistent with definite glaucoma were $\geqslant 10 \mathrm{~dB}$ in depth and $18^{\circ} \times 12^{\circ}$. It was required that the cluster of points in these areas be confined to one horizontal hemifield. The four points along the superior margin of the field were disregarded in grading, as were the nine points surrounding the blind spot.

Table 2 Age and sex distribution of subjects examined $(n=2347)$

\begin{tabular}{lcccccc}
\hline Age group & $\begin{array}{l}\text { Males in } \\
\text { sample }\end{array}$ & \% of sample & \% in population & $\begin{array}{l}\text { Females in } \\
\text { sample }\end{array}$ & \% of sample & \% in population \\
\hline $35-39$ & 206 & 8.8 & 11.9 & 293 & 12.5 & 11.4 \\
$40-49$ & 379 & 16.1 & 16.7 & 367 & 15.6 & 15.0 \\
$50-59$ & 243 & 10.4 & 10.8 & 204 & 8.7 & 9.6 \\
$60-69$ & 221 & 9.4 & 7.9 & 205 & 8.7 & 6.9 \\
$70-79$ & 120 & 5.1 & 3.9 & 42 & 1.8 & 3.3 \\
$80+$ & 51 & 2.2 & 1.4 & 16 & 0.7 & 1.2 \\
Total & 1220 & 52.0 & 52.6 & 1127 & 48.0 & 47.4 \\
\hline
\end{tabular}


Table 3 Intraocular pressure and optic disc profiles

\begin{tabular}{lccccc}
\hline & IOP right & IOP left & CDR right & CDR left & $\begin{array}{c}\text { CDR asymmetry } \\
\text { (left - right) }\end{array}$ \\
\hline Observations (n) & 2329 & 2320 & 2132 & 2140 & 2064 \\
No data & 18 & 27 & 215 & 207 & 283 \\
Mean & 15.0 & 15.0 & 0.34 & 0.34 & 0.007 \\
Median & 14 & 14 & 0.30 & 0.30 & 0.000 \\
SD & 3.7 & 4.4 & 0.14 & 0.14 & 0.07 \\
0.05th percentile & 0 & 0 & 0.10 & 0.10 & -0.49 \\
2.5th percentile & 10 & 10 & 0.15 & 0.15 & -0.10 \\
97.5th percentile & 22 & 22 & 0.70 & 0.70 & 0.15 \\
99.5th percentile & 32 & 45 & 0.85 & 0.85 & 0.30 \\
\hline \multicolumn{7}{l}{} \\
\multicolumn{5}{l}{ CDR distribution in people with normal visual fields has been given previously. } \\
\end{tabular}

If there were pathological features that would explain the presence of a visual field defect (diabetic retinopathy, age related macular degeneration, degenerative myopia, etc), it was not classified as glaucomatous. Glaucoma and suspect glaucoma were diagnosed according to the International Society of Geographical and Epidemiological Ophthalmology (ISGEO) scheme, ${ }^{13}$ outlined in table 1 . Blindness was defined as a visual acuity of $<6 / 60$ in the better eye with the best available refractive correction.

Data were analysed using proprietary statistical software (SPSS, SPSS Inc, USA), and the CSURVEY option in Epi-Info version 6.0. 95\% Confidence intervals for prevalence figures were adjusted for design effect.

\section{RESULTS}

From a total of 3562 eligible subjects, 2347 (65.9\%) were examined. One examination was incomplete. Thirty one villages were randomly selected from 16 unions. The response rate in each union ranged from $62.2 \%$ to $71.1 \%$. Design effects calculated definite plus or minus probable glaucoma were 1.1. Table 2 summarises the age and sex of subjects examined, as well as the percentage distribution in the national population. Table 3 gives details of the IOP and CDR characteristics in the population, including the 97.5th and 99.5th percentile points used in allocating diagnoses. Visual field tests were performed on 975 eyes of 507 individuals (493 right eyes and 482 left eyes). One subject produced a definite field defect in the right eye, with gross right retinal scarring presumed to be secondary to toxoplasmosis. This case was excluded from the diagnosis of glaucoma.

Tables 4 and 5 summarise the characteristics of glaucoma cases detected, according to diagnostic categories 1, 2, and 3. In subjects with "definite" field defects and abnormal features of the optic disc, 10 people met category 1 criteria, as shown in table 4. If people with "probable" and "definite" field defects were included, the number of people with category 1 glaucoma rose to 36 (table 5). Inclusion of those subjects meeting the diagnostic criteria for glaucoma according to categories 2 and 3 brought the total number of cases to 41 (men 21, women 20) and 67 people (39 men and 28 women) respectively, depending on the definition of field loss, as indicated in tables 3 and 4 .

The prevalence of glaucoma according to category l criteria with definite field defects was $1.8 \%$ (95\% CI: 1.3 to 2.4 ). When considering category 1 criteria with definite and probable field defects the prevalence of glaucoma was found to be $2.9 \%$ (95\% CI: 2.3 to 3.6 ). In people aged 40 years and older, these figures rose to $2.1 \%$ (95\% CI: 1.5 to 2.9 ) and $3.1 \%$ (95\% CI: 2.4 to 4.0 ) respectively. In people aged 40 years and older, the prevalence of POAG was $2.5 \%$ (95\% CI: 1.9 to 3.3 ), with PACG and secondary glaucoma having prevalence rates of $0.4 \%$ (95\% CI: 0.2 to 0.8 ) and $0.2 \%$ (95\% CI: 0.1 to 0.5 ) respectively.

Table 6 outlines the age and sex distribution of the glaucoma cases, subdivided into POAG, PACG, secondary, and those of uncertain aetiology. The mechanism of glaucoma was classified as POAG in 29/41 ("definite" field loss alone) and 55/67 ("probable" and "definite" field loss). Therefore, depending on the definition of significant field loss considered, from $71 \%$ to $82 \%$ of glaucoma was POAG. Considering people with definite field loss, $20 \%$ of people with POAG were blind, compared with $33.3 \%$ of those with secondary glaucoma. PACG was the most visually destructive form of glaucoma ( $57 \%$ blind).

Table 7 summarises the prevalence of abnormal findings in examination of the optic disc, IOP or drainage angle by gonioscopy. The prevalence of glaucoma and suspect glaucoma was $11.9 \%$ (95\% CI: 10.2 to 13.8 ) in men and 12.3 (10.5 to 14.4 ) in women. The population prevalence was $12.1 \%$ (95\% CI: 10.8 to 13.5 ). There were 48 people with narrow angles, 11 men and 37 women (3.4:1 women:men).

There were 315 of 2347 people (13.4\%, 95\% CI: 12.1 to 14.9) with a visual acuity $<6 / 60$ in the better eye with

Table 4 Cases of glaucoma-category 1 cases required a "definite" field defect $(n=2347)$

\begin{tabular}{|c|c|c|c|c|c|c|c|c|c|c|}
\hline \multirow[b]{3}{*}{ Age (years) } & \multicolumn{5}{|c|}{ Men } & \multicolumn{5}{|c|}{ Women } \\
\hline & \multicolumn{5}{|c|}{ Diagnostic category } & \multicolumn{5}{|c|}{ Diagnostic category } \\
\hline & 1 & 2 & 3 & No & $\begin{array}{l}\text { Prevalence \% } \\
(95 \% \text { CI) }\end{array}$ & 1 & 2 & 3 & No & $\begin{array}{l}\text { Prevalence \% } \\
(95 \% \mathrm{CI})\end{array}$ \\
\hline $35-39$ & 1 & 2 & 0 & 206 & $1.5(0.5$ to 4.2$)$ & 0 & 0 & 0 & 293 & 0.0 (0.0 to 1.3$)$ \\
\hline $40-49$ & 3 & 2 & 1 & 379 & $1.6(0.7$ to 3.4$)$ & 0 & 3 & 2 & 367 & 1.4 to $(0.6$ to 3.1$)$ \\
\hline $50-59$ & 3 & 1 & 1 & 243 & $2.1(0.9$ to 4.7$)$ & 1 & 4 & 1 & 204 & $2.9(1.4$ to 6.3$)$ \\
\hline $60-69$ & 1 & 2 & 0 & 221 & $1.4(0.5$ to 3.9$)$ & 0 & 5 & 3 & 205 & 3.9 (2.0 to 7.5$)$ \\
\hline 70-79 & 1 & 1 & 1 & 120 & 2.5 (0.9 to 7.1$)$ & 0 & 0 & 1 & 42 & $2.4(0.4$ to 12.3$)$ \\
\hline $80+$ & 0 & 1 & 0 & 51 & $2.0(0.3$ to 10.3$)$ & 0 & 0 & 0 & 16 & $0.0(0.0$ to 19.4$)$ \\
\hline Total & 9 & 9 & 3 & 1220 & 1.8 (1.2 to 2.7$)$ & 1 & 12 & 7 & 1127 & 1.8 (1.2 to 2.7$)$ \\
\hline \multicolumn{6}{|c|}{ Prevalence $\%(95 \% \mathrm{Cl})$ for men and women combined } & \multicolumn{5}{|c|}{$1.8(1.3$ to 2.4$)$} \\
\hline
\end{tabular}


Table 5 Cases of glaucoma-category 1 cases combining "probable and definite" field defects $(n=2347$ )

\begin{tabular}{|c|c|c|c|c|c|c|c|c|c|c|}
\hline \multirow[b]{3}{*}{ Age (years) } & \multicolumn{5}{|c|}{ Men } & \multicolumn{5}{|c|}{ Women } \\
\hline & \multicolumn{5}{|c|}{ Diagnostic category } & \multicolumn{5}{|c|}{ Diagnostic category } \\
\hline & 1 & 2 & 3 & No & $\begin{array}{l}\text { Prevalence \% } \\
(95 \% \mathrm{Cl})\end{array}$ & 1 & 2 & 3 & No & $\begin{array}{l}\text { Prevalence \% } \\
(95 \% \mathrm{Cl})\end{array}$ \\
\hline $35-39$ & 5 & 2 & 0 & 206 & $3.4(1.7$ to 6.8$)$ & 2 & 0 & 0 & 293 & $0.7(0.2$ to 2.5$)$ \\
\hline $40-49$ & 10 & 2 & 1 & 379 & $3.3(1.9$ to 5.6$)$ & 5 & 3 & 2 & 367 & 2.7 (1.4 to 4.8$)$ \\
\hline $50-59$ & 7 & 1 & 1 & 243 & $3.6(1.9$ to 6.6$)$ & 1 & 4 & 1 & 204 & $2.9(1.4$ to 6.3$)$ \\
\hline $60-69$ & 3 & 2 & 0 & 221 & $2.3(1.0$ to 5.2$)$ & 1 & 5 & 3 & 205 & $4.4(2.3$ to 8.1$)$ \\
\hline $70-79$ & 2 & 1 & 1 & 120 & $3.2(1.3$ to 8.0$)$ & 0 & 0 & 1 & 42 & $2.4(0.4$ to 12.3$)$ \\
\hline $80+$ & 0 & 1 & 0 & 51 & $2.0(0.3$ to 10.3$)$ & 0 & 0 & 0 & 16 & $0(0.0$ to 19.4$)$ \\
\hline Total & 27 & 9 & 3 & 1220 & $3.2(2.3$ to 4.3$)$ & 9 & 12 & 7 & 1127 & $2.5(1.7$ to 3.6$)$ \\
\hline \multicolumn{6}{|c|}{ Prevalence $\%(95 \% \mathrm{Cl})$ for men and women combined } & \multicolumn{4}{|c|}{$2.9(2.3$ to 3.6$)$} & \\
\hline
\end{tabular}

available refractive correction. There were a further 236 people who were blind in at least one eye. The prevalence of blindness in at least one eye was $20.1 \%$ (95\% CI: 18.5 to 21.8 ). In people aged 40 years and older, the prevalence of blindness was $16.8 \%$ (95\% CI: 15.2 to 18.6 ), and uniocular blindness $28.7 \%$ (95\% CI: 26.7 to 30.8 ). There were 41 people who achieved a visual acuity of $6 / 36$ or better with a pinhole ( $13.0 \%$ of those blind).

\section{DISCUSSION}

This work gives new information on the prevalence and mechanism of glaucoma in one region of the Indian subcontinent. While there were imperfections in the design and execution of the study, it does highlight several problems that must be addressed and overcome if definitive data are to be produced from subsequent studies. The response rate of 66\% was rather low, although 2347 subjects were examined. We are uncertain which factors may have led to nonattendance. This may have resulted in either an underestimate or overestimate of prevalence.

We have cited figures for the prevalence of glaucoma of $2.1 \%$ and $3.1 \%$ in the population aged 40 years and older, based on differing definitions of significant visual field loss. The difference between these two figures underlines the dilemma facing all groups working in the area of glaucoma epidemiology. The greatest determinant of glaucoma prevalence in a population is the method used to define the disease. $^{14}$ By calculating the distribution of CDR in our population we have confirmed that the distribution of vertical CDR and CDR asymmetry in Bangladeshi adults is similar to that of European and other Asian populations. Of the two definitions of visual field loss, the "definite and probable" group represents a definition that has been most widely used by other investigators. Therefore, the prevalence figure of $3.1 \%$ is probably the most appropriate for comparative purposes. This figure is high, especially as it represents a population in which $40 \%$ of people aged 40 years and above were in the 40-49 year age group, implying the population as a whole has a pyramidal age structure, with a smaller proportion of older people than in an industrialised country. With approximately 26 million adults aged 40 years and older in Bangladesh, it is estimated that there would be as many as 586000 people in the country with glaucoma. ${ }^{15}$

Striking features of the data are that the prevalence of glaucoma is high in young people, and does not show a clear increase with age. Upon inspection of the age related trend for glaucoma in tables 3, 4, and 7, the prevalence results for the 60-69 year old group seems incongruous with the results in the 50-59 and 70-79 year age groups, especially among men. When attempting to identify possible explanations for this finding it would be useful to consider that the majority of adults in Bangladesh do not know their exact age. Mandatory birth registration was only initiated in Bangladesh in 1999; as such, most adults-especially those living in rural areashave no means to verify their own age. During the interview and examination process efforts were made to estimate the age of subjects who were seemingly unsure of their age or in those cases when a reported age did not appear realisticthat is, either too old or too young.

A potential source of error in survey research is interobserver variation in grading. ${ }^{14}$ However, with a single observer $(\mathrm{ZH})$ performing all gonioscopic and disc examinations, any grading bias should have been limited to a systematic effect. Furthermore, we used a standardised, reproducible method of allocating the diagnosis of glaucoma, eliminating individual interpretation in the diagnostic process. Therefore, at least part of this trend must be seen as genuine. The population of Bangladesh is subjected to environmental hardships that few other populations on earth routinely encounter. Sadly, cyclical severe flooding and

Table 6 Characteristics of glaucoma cases detected

\begin{tabular}{|c|c|c|c|c|c|c|c|c|c|c|}
\hline \multirow[b]{2}{*}{ Characteristics } & \multicolumn{5}{|c|}{ Field defects -"definite" } & \multicolumn{5}{|c|}{ Field defects - "definite" and "probable" } \\
\hline & POAG & PACG & Secondary & Other & Total & POAG & PACG & Secondary & Other & Total \\
\hline Sex (M:F) & 19:10 & $1: 6$ & $0: 3$ & $1: 1$ & $21: 20$ & $37: 18$ & $1: 6$ & $0: 3$ & $1: 1$ & $39: 28$ \\
\hline Mean age & 53 & 48 & 68 & 68.5 & 55 & 51 & 51 & 63 & 68 & 67 \\
\hline Range & $35-85$ & $42-62$ & $62-69$ & $68-72$ & $35-85$ & $35-85$ & $42-62$ & $59-68$ & $65-72$ & $35-85$ \\
\hline Blind in one or both eyes & 10 & 7 & 3 & 2 & 22 & 13 & 7 & 3 & 2 & 25 \\
\hline Bilaterally blind & 7 & 4 & 1 & 2 & 14 & 9 & 4 & 1 & 2 & 16 \\
\hline Diagnostic category 1 & 10 & 0 & 0 & 0 & 10 & 36 & 0 & 0 & 0 & 36 \\
\hline Diagnostic category 2 & 16 & 5 & 0 & 0 & 21 & 16 & 5 & 0 & 0 & 21 \\
\hline Diagnostic category 3 & 3 & 2 & 3 & 2 & 10 & 3 & 2 & 3 & 2 & 10 \\
\hline Total & 29 & 7 & 3 & 2 & 41 & 55 & 7 & 3 & 2 & 67 \\
\hline
\end{tabular}


Table 7 Percentage prevalence $(95 \% \mathrm{Cl})$ of glaucoma and suspect glaucoma based on abnormal findings for optic disc, IOP and drainage angle

\begin{tabular}{|c|c|c|c|c|c|c|c|c|}
\hline \multicolumn{5}{|l|}{ Men } & \multicolumn{4}{|c|}{ Women } \\
\hline Age (years) & Disc & IOP & Angle & Total & Disc & IOP & Angle & Total \\
\hline $\begin{array}{l}35-39 \\
40-49 \\
50-59 \\
60-69 \\
70-79 \\
80+ \\
\text { Total } \\
\text { Prevalence \% }\end{array}$ & $\begin{array}{r}6.9 \\
8.9 \\
8.9 \\
12.4 \\
9.5 \\
5.9 \\
\\
\text { Cl) for } r\end{array}$ & $\begin{array}{l}4.4 \\
4.2 \\
4.5 \\
5.0 \\
5.0 \\
6.0 \\
\\
\text { d wom }\end{array}$ & $\begin{array}{l}1.9 \\
0.5 \\
0.8 \\
0.9 \\
0.8 \\
0 \\
\text { nbined }\end{array}$ & $\begin{array}{l}11.2 \\
11.9 \\
11.5 \\
13.6 \\
11.7 \\
9.8 \\
11.9(10.2 \text { to } 13.8)\end{array}$ & $\begin{array}{l}5.5 \\
9.3 \\
9.0 \\
9.2 \\
3.2 \\
0.0\end{array}$ & $\begin{array}{l}1.0 \\
4.1 \\
6.9 \\
7.3 \\
7.1 \\
0 \\
\\
13.5)\end{array}$ & $\begin{array}{l}1.7 \\
3.0 \\
4.9 \\
4.4 \\
4.8 \\
0\end{array}$ & $\begin{array}{l}8.2 \\
13.4 \\
14.7 \\
15.1 \\
11.9 \\
0 \\
12.3(10.5 \text { to } 14.4)\end{array}$ \\
\hline
\end{tabular}

famine are common features of life in Bangladesh. It may be that there is selective (that is, increased) mortality among those who have glaucoma at an early age. Follow up studies have identified increased mortality rates among glaucoma patients in the United States when compared with nonglaucomatous subjects ${ }^{16}$; similarly, people with cataract who do not undergo surgery were shown to have increased mortality when compared with either those who underwent surgery or with people without operable cataract patients. ${ }^{17}$ Likewise, it has been reported in Australia that visual impairment $(<6 / 12$ visual acuity) is associated with more than double the risk of death over 5 years of follow up. ${ }^{18}$ It may be that glaucoma in Bangladesh differs from the expected age related pattern identified in other settings as a result, in part, of the relatively low life expectancy of the population together with increased mortality among people who develop this condition.

Hospital data have previously suggested that glaucoma on the Indian subcontinent was of equal proportions of POAG and PACG. ${ }^{19}{ }^{20}$ Secondary glaucoma, while believed to be a significant problem in India, is even less well documented. Our data suggest that POAG was the predominant mechanism, accounting for $70 \%$ to $80 \%$ of all glaucomatous optic neuropathy. Despite the higher prevalence of POAG, 57\% of PACG sufferers had severe uniocular loss of vision (VA $<6 / 60$ ), whereas only $16-24 \%$ (depending on definition) of those with POAG were "blind." However, in absolute terms, POAG caused double the number of cases of blindness that PACG did. The fact that PACG was substantially less prevalent than POAG is one reason we believe that response bias has not severely affected our estimate of glaucoma prevalence. In hospital based studies, it is widely believed that PACG is over-represented as a consequence of its greater propensity to cause symptoms. Hence, if response bias were a significant factor in this study, one would expect PACG to account for a higher prevalence than POAG.

In summary, these data suggest the prevalence of glaucoma in Bangladesh is high. POAG is the most common form of glaucoma, although PACG and secondary glaucoma were the most visually destructive forms of the disease in those affected. The age distribution of glaucoma is different from that seen in other populations, and further population based, longitudinal studies are required to explain this trend.

\section{ACKNOWLEDGEMENTS}

This work was supported by a grant from the International Glaucoma Association.

\section{Authors' affiliations}

M M Rahman, N Rahman, MAI Institute of Ophthalmology and Islamia Eye Hospital, Farmgate, Dhaka, Bangladesh

P J Foster, G J Johnson, Division of Epidemiology, Institute of Ophthalmology, Bath Street, London, UK

P J Foster, Glaucoma Research Unit, Moorfields Eye Hospital, City Road, London, UK

Z Haque, A U Zaman, Bangladesh Eye Care Society, Lalmatia, Dhaka, Bangladesh

B Dineen, Clinical Research Unit, London School of Hygiene and

Tropical Medicine, Keppel Street, London, UK

\section{REFERENCES}

1 World Health Organization. World health report. Geneva: WHO, 1998.

2 Fraser S, Bunce C, Wormald R, et al. Deprivation and late presentation of glaucoma: case-control study. BMJ 2001;322:639-43.

3 US Census Bureau. IDB summary demographic data, US Census Bureau, 2004.

4 Thylefors B, Négrel A-D, Pararajasegaram R, et al. Global data on blindness. Bull World Health Organ 1995;73:115-21.

5 Dandona L, Dandona R, Naduvilath TJ, et al. Is current eye-care-policy focus almost exclusively on cataract adequate to deal with blindness in India? Lancet 1998;351:1312-16

6 Pokharel GP, Regmi G, Shrestha SK, et al. Prevalence of blindness and cataract surgery in Nepal. Br J Ophthalmol 1998;82:600-5.

7 Quigley HA. Number of people with glaucoma worldwide. Br J Ophthalmol 1996;80:389-93

8 Dandona L, Dandona R, Srinivas $M$, et al. Open-angle glaucoma in an urban population in southern india. The Andhra Pradesh Eye Disease Study. Ophthalmology 2000;107:1702-9.

9 Dandona L, Dandona R, Mandal P, et al. Angle-closure glaucoma in an urban population in southern india. The Andhra Pradesh Eye Disease Study. Ophthalmology 2000;107:1710-16.

10 Jacob A, Thomas R, Koshi SP, et al. Prevalence of primary glaucoma in an urban south Indian population. Indian J Ophthalmol 1998;46:81-6.

11 Ramakrishnan R, Nirmalan PK, Krishnadas R, et al. Glaucoma in a rural population of southern India: the Aravind Comprehensive Eye Survey. Ophthalmology 2003;110:1484-90.

12 Rahman MM, Rahman N, Munshi MA. Glaucoma prevalence survey in Bangladesh-1993. Dhaka, Bangladesh: Bangladesh Eye Care Society, 1993.

13 Foster PJ, Buhrmann RR, Quigley HA, et al. The definition and classification of glaucoma in prevalence surveys. $\mathrm{Br} J$ Ophthalmol 2002;86:238-42.

14 Wolfs RC, Borger PH, Ramrattan RS, et al. Changing views on open-angle glaucoma: definitions and prevalences -The Rotterdam Study. Invest Ophthalmol Vis Sci 2000;41:3309-21.

15 US Census Bureau. IDB summary demographic data for Bangladesh, US Census Bureau, 2003.

16 Lee DJ, Gomez-Marin O, Lam BL, et al. Glaucoma and survival: the National Health Interview Survey 1986-1994. Ophthalmology 2003;110:1476-83

17 McGwin G, Owsley C, Gauthreaux S. The association between cataract and mortality among older adults. Ophthalmic Epidemiol 2003;10:107-19.

18 McCarty CA, Nanjan MB, Taylor HR. Vision impairment predicts 5 year mortality. Br J Ophthalmol 2001;85:322-6.

19 Pararajasegaram P. Glaucoma pattern in Ceylon. Trans Asia Pacific Acad Ophthalmol 1968;3:274-8.

20 Sihota R, Agarawal HC. Profile of the subtypes of angle-closure glaucoma in a tertiary hospital in northern India. Indian J Ophthalmol 1998;46:25-9. 